\title{
Relato de Rhizoctonia solani AG-4 HG I em crisântemo (Papiro Branco e Amarelo) e $R$. solani AG-4 HG III em gipsófila no estado de São Paulo, Brasil, e sua patogenicidade cruzada
}

\author{
César Júnior Bueno ${ }^{1}$, Wagner Bettiol ${ }^{2}$, Edisson Chavarro Mesa $^{3}$, Paulo Cézar Ceresini ${ }^{3}$
}

\begin{abstract}
${ }^{1}$ Instituto Biológico/APTA. Rodovia Heitor Penteado, Km 3, CEP 13092-543, Campinas - SP. ${ }^{2}$ Embrapa Meio Ambiente. Rodovia SP 340 , Km 127,5, Caixa Postal 69, CEP 13820-000, Jaguariúna - SP. ${ }^{3}$ Universidade Estadual Paulista (UNESP), Campus de Ilha Solteira, Departamento de Fitossanidade, Engenharia Rural e Solos, CEP 15385-000, Ilha Solteira - SP.
\end{abstract}

Autor para correspondência: César Júnior Bueno (cjbueno@biologico.sp.gov.br)

Data de chegada: 15/04/2012. Aceito para publicação em: 01/10/2013.

\section{RESUMO}

Bueno, C.J.; Bettiol, W.; Mesa, E.M.; Ceresini, P.C. Relato de Rhizoctonia solani AG-4 HG I em crisântemo (Papiro Branco e Amarelo) e R. solani AG-4 HG III em gipsófila, no estado de São Paulo, Brasil, e sua patogenicidade cruzada. Summa Phytopathologica, v.39, n.4, p.286-289, 2013.

Atualmente, grupamento de anastomose (AG) de Rhizoctonia sp. em crisântemo e ocorrência deste fungo em gipsófila ainda não foram relatados no Brasil. Assim, realizou-se teste de patogenicidade normal e cruzada e sequenciamento da região ITS-5.8S rDNA para identificar o AG de isolado obtido de plantas de crisântemo (Papiro Branco) e de gipsófila, ambas originárias de Holambra / São Paulo, Brasil. Após os testes, relata-se pela primeira vez a ocorrência de $R$. solani AG-4 HG I em crisântemo (Papiro Branco e Amarelo) e R. solani AG-4 HG III em gipsófila, no estado de São Paulo, Brasil, e, também, a sua patogenicidade cruzada.

Palavras-chave adicionais: ornamental, fungo de solo, patogenicidade, Chrisanthemum spp.

\section{ABSTRACT}

Bueno, C.J.; Bettiol, W.; Mesa, E.M.; Ceresini, P.C. Report of Rhizoctonia solani AG-4 HG I on chrysanthemum (White and Yellow Papyrus) and $R$. solani AG-4 HG III on gypsophila in the São Paulo State, Brazil, and their cross pathogenicity. Summa Phytopathologica, v.39, n.4, p.286-289, 2013.

Currently, anastomosis groups (AG) of Rhizoctonia sp. on chrysanthemum and occurrence of this fungus on gypsophila have not been reported in Brazil. However, in the present study, normal and cross pathogenicity and sequencing of ITS-5.8S rDNA regions were used to confirm the AG of isolate of Rhizoctonia sp. obtained from chrysanthemum (White Papyrus) and from gypsophila plants cultivated in Holambra / São Paulo, Brazil. After these tests, it was confirmed the report of Rhizoctonia solani AG-4 HG I on chrysanthemum (White and Yellow Papyrus) and $R$. solani AG-4 HG III on gypsophila in the São Paulo state, Brazil, and also their cross pathogenicity.

Additional keywords: ornamental, soilborne phytopathogenic fungi, pathogenicity, Chrisanthemum spp.

O crisântemo é uma das ornamentais mais cultivadas no Brasil, com expressão nos Estados de São Paulo, Rio de Janeiro e Minas Gerais. Há cultivares para corte, para vaso e jardim $(1,3)$. Gypsophila paniculata L., ornamental conhecida como mosquitinho, pertence à família Caryophyllaceae Lindl. e com ampla distribuição no mundo (4). As suas inflorescências apresentam flores pequenas e brancas, sendo comercializadas, principalmente, para confecção de arranjos e buquês (6).

Os patógenos de solo Rhizoctonia sp. e Pythium sp. são relatados como prejudiciais para a cultura do crisântemo, principalmente na fase do enraizamento (2). Relatos de doenças em gipsófila, no Brasil, são escassos. Sabe-se que gipsófila é propagado vegetativamente (6), podendo ocorrer, neste método, problemas fitossanitários, principalmente com fungos de solo.

Em Março de 2009, plantas de crisântemo Papiro Branco para vaso, oriundas da cidade de Holambra-São Paulo, foram recebidas no Instituto Biológico de Campinas/SP. Deste material, isolou-se Rhizoctonia sp.. O isolado foi depositado na coleção do Instituto e recebeu o número IBRS01. Na coleção de culturas de fitopatógenos da Embrapa Meio Ambiente, há um isolado de Rhizoctonia sp., da cultura de gipsófila procedente da cidade de Holambra-São Paulo, de 1991. O isolado foi depositado, também, na coleção do Instituto e recebeu o número IBRS02.

Como não há relato, no Brasil, do grupamento de anastomose (AG) de Rhizoctonia sp. que ocorre em crisântemo e, também, de relato de ocorrência deste fungo no mosquitinho, o presente trabalho teve como objetivos, além da realização do teste de patogenicidade normal e cruzada dos isolados, também a identificação do AG dos mesmos.

A produção de inóculo, bem como a infestação em substrato areno- 
orgânico (Tropstrato HT à base de casca de Pinus) esterilizado (2 h a $1 \mathrm{~atm})$, seguiram a metodologia de Lefèvre \& Souza (5). Para o teste de patogenicidade normal foram obtidas mudas sadias das cultivares Papiro Branco e Papiro Amarelo de crsisântemo, e de Gipsófila, a cultivar Allegro ${ }^{\circledast}$. O sistema radicular das mudas foi ou não podado e, também, causou-se ou não ferimento no colo. Mudas de Papiro Amarelo, sem raiz, foram transplantadas diretamente sem ferimento no colo. O tratamento controle recebeu plantas idênticas ao do tratamento inoculado, mas com o substrato não infestado pelo fungo. Os vasos foram distribuídos em blocos, com 10 tratamentos e cinco repetições, sendo a repetição constituída por um vaso com uma planta. Após a incubação em câmara úmida por 24 horas, as plantas foram mantidas em casa de vegetação por 14 dias. Para a patogenicidade cruzada, as mudas não receberam ferimento no colo e nem corte no sistema radicular. O isolado de gipsófila foi inoculado em mudas de Papiro Amarelo e o isolado de crisântemo em gipsófila. As demais fases foram idênticas ao da patogenicidade normal. Todas as plantas foram avaliadas quanto a incidência e a severidade da doença (escala de notas) (Tabela 1). Após a avaliação, procedeu-se ao reisolamento do agente causal dos sintomas de todas as plantas, completando-se os postulados de Kock do teste de patogenicidade.

A identificação do AG dos isolados foi realizada por meio de construção de árvore filogenética (Figura 2), utilizando o programa Mega 5.0. Para tanto, efetuou-se extração de DNA dos isolados, amplificação via PCR, clonagem de amplicons de PCR e o sequenciamento de bases da região ITS-5.8S do rDNA (9).

O isolado de Rhizoctonia sp. de crisântemo foi patogênico para as duas cultivares de crisântemo e em todas as formas de tratamentos, mas muito mais agressivo no Papiro Amarelo do que no Papiro Branco.
A poda no sistema radicular e o ferimento no colo causaram maior severidade de doença no Papiro Branco em relação ao mesmo material sem poda nas raízes e ferimento no colo (Tabela 1). Assim, o prejuízo que o fungo Rhizoctonia sp. pode causar na fase de enraizamento da cultura é importante. Além de lesões escuras na região do colo, observaram-se folhas basais amareladas, necrosadas e o sistema radicular totalmente escuro, nos tratamentos inoculados (Figura 1).

O isolado de Rhizoctonia sp. de gipsófila foi patogênico em mudas de gipsófila com poda ou não no sistema radicular e com ferimento ou não no colo das plantas (Tabela 1). Isto ocorreu, provavelmente, devido à arquitetura das mudas, ou seja, no plantio, o colo e as folhas das mudas ficam em contato com o substrato infestado com o fungo. Os sintomas gerais observados nas plantas foram podridão no colo e na base das folhas, inclusive nas do ponteiro, levando as folhas a se tornarem amarelas e murchas. No entanto, as mudas que tiveram as raízes podadas e o colo ferido tiveram as folhas do ponteiro totalmente apodrecidas (Figura 1). Ambos os isolados de Rhizoctonia sp. foram reisolados das plantas sintomáticas, comprovando-se a patogenicidade nos seus respectivos hospedeiros. Além disso, houve patogenicidade cruzada nos materiais (Tabela 1) bem como a comprovação disto por meio de reisolamento dos isolados.

O isolado de crisântemo (KF746162) foi identificado molecularmente como Rhizoctonia solani AG-4 HGI, apresentando 99\% de similaridade genética com dois isolados padrões representativos deste AG e do subgrupo obtidos do GenBank-NCBI, enquanto que o isolado de gipsófila (KF746163) foi identificado como R. solani AG4 HG III, apresentando 99\% de similaridade genética, também, com dois isolados padrões deste AG e do subgrupo, obtidos junto ao GenBank-NCBI (Figura 2).

Tabela 1. Patogenicidade normal e cruzada com dois isolados de Rhizoctonia sp., sendo um de crisântemo e outro de gipsófila.

Patogenicidade normal

\begin{tabular}{|c|c|c|c|c|c|c|c|c|c|}
\hline \multirow{3}{*}{$\begin{array}{l}\text { Cultivar } \\
\text { Crisântemo- Papiro Branco }\end{array}$} & \multirow{3}{*}{$\begin{array}{l}\text { Tratamento } \\
\text { Inoculado }\end{array}$} & \multirow{3}{*}{$\begin{array}{l}\text { Sistema radicular e colo } \\
\text { Normal }\end{array}$} & \multirow{2}{*}{\multicolumn{5}{|c|}{ Severidade da doença ${ }^{1}$}} & \multicolumn{2}{|c|}{ Média } \\
\hline & & & & & & & & \multirow{2}{*}{$\frac{\text { Severidade }}{2,0 \mathrm{c}^{2}}$} & \multirow{2}{*}{$\frac{\text { Incidência(\%) }}{40}$} \\
\hline & & & $0^{3}$ & 5 & 0 & 0 & 5 & & \\
\hline & & Podado e ferido & 4 & 4 & 5 & 3 & 5 & $4,2 \mathrm{~b}$ & 100 \\
\hline & Testemunha & Normal & 0 & 0 & 0 & 0 & 0 & $0 \mathrm{~d}$ & 0 \\
\hline & & Podado e ferido & 0 & 0 & 0 & 0 & 0 & $0 \mathrm{~d}$ & 0 \\
\hline \multirow[t]{2}{*}{ Crisântemo- Papiro Amarelo } & Inoculado & Normal & 6 & 6 & 6 & 6 & 6 & $6,0 \mathrm{a}$ & 100 \\
\hline & Testemunha & Normal & 0 & 0 & 0 & 0 & 0 & $0 \mathrm{~d}$ & 0 \\
\hline \multirow[t]{7}{*}{ Gipsófila } & Inoculado & Normal & & & & & & & 100 \\
\hline & & Podado e ferido & & & & & & & 100 \\
\hline & Testemunha & Normal & & & & & & & 0 \\
\hline & & Podado e ferido & & & & & & & 0 \\
\hline & & \multicolumn{8}{|l|}{ Patogenicidade cruzada } \\
\hline & Procedência & Tratamento & \multirow{2}{*}{\multicolumn{5}{|c|}{ Severidade da doença ${ }^{1}$}} & \multicolumn{2}{|c|}{ Média } \\
\hline & do isolado & & & & & & & Severidade & Incidência(\%) \\
\hline \multirow[t]{2}{*}{ Crisântemo- Papiro Amarelo } & Gipsófila & Inoculado & $0^{3}$ & 5 & 6 & 6 & 6 & 4,6 & 80 \\
\hline & & Testemunha & 0 & 0 & 0 & 0 & 0 & 0 & 0 \\
\hline \multirow[t]{2}{*}{ Gipsófila } & Crisântemo & Inoculado & & & & & & & 100 \\
\hline & & Testemunha & & & & & & & 0 \\
\hline
\end{tabular}

${ }^{1}$ Escala de notas: $0=$ sem infecção; $1=$ descoloração típica de raízes, colo e caule; $2=$ lesões pequenas; $3=$ lesões largas; $4=$ lesões extensas (50\% do colo e caule); $5=$ plantas completamente aneladas; e 6=damping-off (tombamento) de pós-emergência.

${ }^{2}$ Letras minúsculas, na coluna, comparam os tratamentos entre os materiais, segundo o teste não-paramétrico de Friedman, complementado com o teste T ao nível de 5\% de probabilidade; ${ }^{3}$ Média de cinco repetições. 

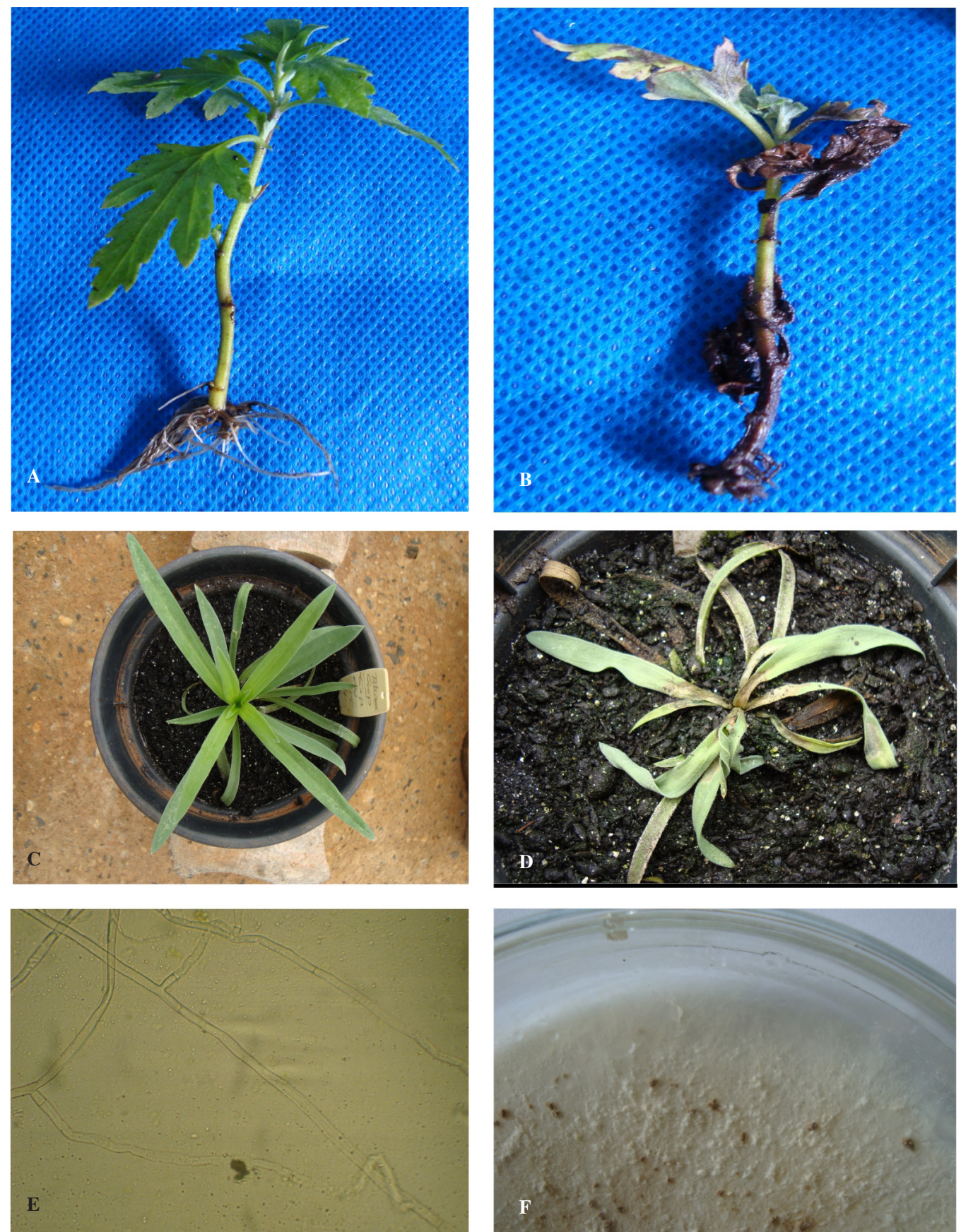

Figura 1. A - Planta sadia de crisântemo Papiro Branco; B - Papiro Branco retirada de um vaso contendo substrato infestado e que teve o sistema radicular podado e o colo ferido, apresentando os sintomas de Rhizoctonia sp. no seu sistema radicular, no colo e sintomas reflexos, na parte aérea; C - Planta de gipsófila normal e sadia; D - Planta de gipsófila apresentando sintomas de Rhizoctonia sp. nas folhas; E - Hifa do isolado de Rhizoctonia sp. de crisântemo; F - Colônia do isolado de Rhizoctonia sp. de gipsófila, crescido em meio de batata-dextrose-ágar.

Na Itália, o fungo $R$. solani AG-4 foi descrito em crisântemo e em outras ornamentais (8). No Estado do Pará/Brasil há relato de ocorrência de Tanatephorus cucumeris, fase perfeita de R. solani, em Chrysanthemum indicus (7). Assim, reporta-se pela primeira vez $R$. solani AG-4 HG I em crisântemo de vaso, causando patogenicidade nas cultivares Papiro Branco e Amarelo, no Estado de São Paulo, Brasil, sendo essa doença importante, principalmente, na fase de enraizamento dos materiais.

Na Polônia há relato de isolamento de $R$. solani, em planta doente de G. paniculata (10). No Brasil, não há descrição oficial dessa doença em gipsófila. Portanto, esse é o primeiro relato de R. solani AG-4 HG
III em gipsófila, no Estado de São Paulo, Brasil.

O AG-4, subdividido em três subgrupos HG I, HG II e HG III, é descrito na literatura como um grupamento que não é tão específico em termos de hospedeiro, podendo causar podridão de sementes, damping off de pré e pós-emergência e, ocasionalmente, podridão de raízes em diversas culturas de importância econômica no Brasil (9). Isto explica a ocorrência da patogenicidade cruzada pelos isolados de Rhizoctonia do AG-4 nos materiais de crisântemo e gipsófila. Há ainda descrição, no Brasil, de ocorrência de $R$. solani AG-4 HGI nas plantas infestantes beldroega (Portulaca oleracea L.), juá-de-capote (Nicandra physaloides L. Pers.) e maria-pretinha (Solanum americanum Mill); e 

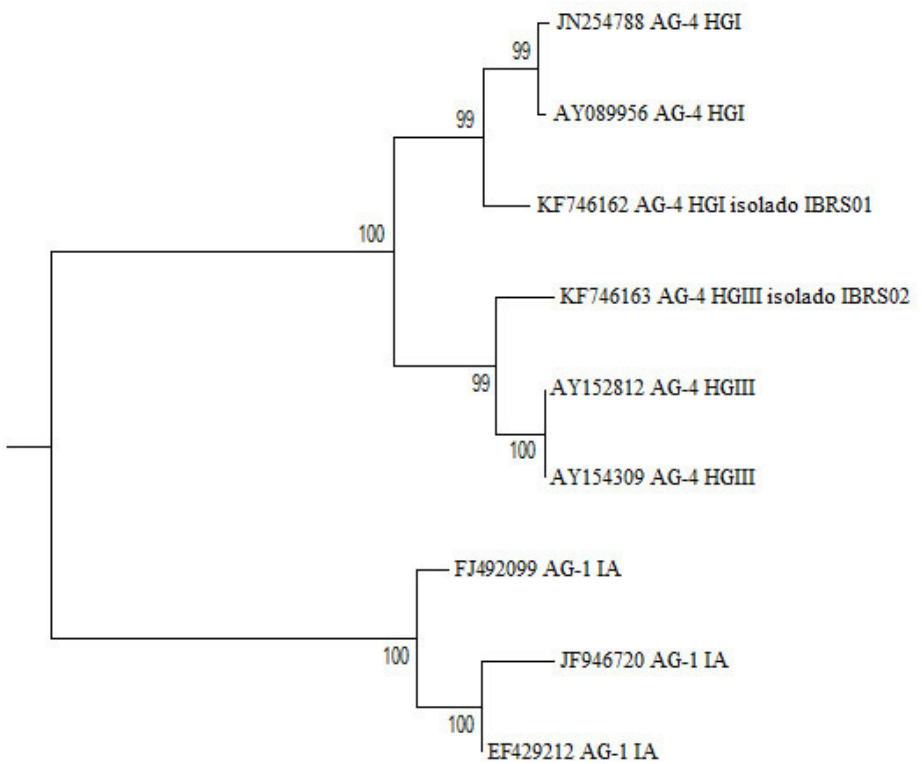

0.02

Figura 2. Árvore filogenética exibindo a relação entre os isolados de Rhizoctonia solani AG-4 subgrupos HGI e HGIII e de $R$. solani AG-1 do GENBANK-NCBI com os isolados de Rhizoctonia de crisântemo (IBRS01 - KF746162) e de gipsófila (IBRS02 - KF746163). A árvore foi construída com base em sequências da região ITS-5.8S do rDNA dos isolados. A história evolutiva foi inferida pelo método de Neighbor-Joining. A percentagem de árvores idênticas em que os taxa associados são agrupados no teste de bootstrap (2500 réplicas) são mostrados ao lado dos ramos.

R. solani AG-4 HGIII em caruru (Amaranthus hybridus L.) (9). Isto complica ainda mais fontes potenciais de inóculo deste patógeno. Assim, cuidados devem ser tomados com o AG-4 de Rhizoctonia na hora de se explorar uma atividade agrícola, a saber: 1) conhecer o histórico de plantio de culturas anteriores, quando da aquisição de uma área; 2) verificar a lista completa de hospedeiros potenciais deste grupamento de anastomose; 3 ) estar atento à cultura a ser utilizada em sistema de rotação de culturas, como medida de controle e etc.

Concluindo, relata-se pela primeira vez a ocorrência de Rhizoctonia solani AG-4 HG I em crisântemo (Papiro Branco e Amarelo) e $R$. solani AG-4 HG III em gipsófila, no estado de São Paulo, Brasil, e, também, a sua patogenicidade cruzada.

\section{AGRADECIMENTOS}

Os autores agradecem Ivone Swart Schoenmaker, que forneceu plantas doentes de Papiro Branco para isolamento, ao Sr. Marcelo A. F. Raposa, da empresa Dekker Chrysanten Brasil LTDA. e, também, ao Sr. Olimar Amaral, da empresa Bio Plug, produtor de Gipsófila em Atibaia-São Paulo, que forneceram respectivamente mudas sadias de crisântemo e de gipsófila para realização dos ensaios. Agradecemos, também, a Dra. Janaína M. de Marques, da empresa Laboratório Atena, que nos forneceu o contato do Sr. Olimar e gentilmente nos acompanhou até a propriedade.

\section{REFERÊNCIAS BIBLIOGRÁFICAS}

1. Bellé, R. A. Apostila didática de floricultura. Santa Maria, 1998. 142 p.

2. Coutinho, L.N.; Russomanno, O.M.R.; Toföli, J.G.; Domingues, R.J.; Oliveira, S.H.F.; Figueiredo, M.B. Doenças fúngicas. In: Imenes, S.L.; Alexandre, M.A.V. (Org.). Aspectos Fitossanitários do Crisântemo. São Paulo: Instituto Biológico, 1996. p.23-34.

3. Cuquel, F.L.; Minami, K. Enraizamento de estacas de crisântemo [Dendranthema morifolium (Ramat.) TZVELEV] tratadas com ácido indolbutírico veiculado em talco. Scientia Agricola, Piracicaba, v. 51, n. 1, p. 28-35, 1994.

4. Gemtchujnicov, I.D. Família Cariophilaceae Lindl. In: Gemtchujnicov, I.D. Manual de taxonomia vegetal, São Paulo: Ceres, v.1, p. 228-230, 1976.

5. Lefèvre, A.F.; Souza, N.L. Lethal temperature determination for Rhizoctonia solani and Sclerotium rolfsii, and solarization effect in the soil temperature. Summa Phytopathologica, Jaboticabal, v. 19, p. 107-112, 1993.

6. Lorenzi, H.; Souza, H.M. Plantas ornamentais do Brasil Arbustivas, herbaceas e trepadeiras. São Paulo: Plantarum, 1995, $720 \mathrm{p}$.

7. Nunes, M.A.L.; Oliveira, F.C.; Teixeira, R.V.R. Ocorrência de Tanatephorus cucumeris em crisântemo (Chrysanthemum indicus) no Estado do Pará. Fitopatologia Brasileira, Brasília, v.18 (Suplemente), p.286, 1993.

8. Pasini, C.; Berio, T.; Curir, P.; D'Aguila, F. Further characterization of Rhizoctonia solani isolated from carnation and other ornamental plants. Informatore Fitopatologico, Bologna, v. 46, p. 33-36, 1996.

9. Silva-Barreto, F.A.S.; Pereira, W.V.; Ciampi, M.B.; Câmara, M.P.S.; Ceresini, P.C. Associação de Rhizoctonia solani Grupo de Anastomose 4 (AG-4 HGI e HGIII) à espécies de plantas invasoras de área de cultivo de batata. Summa Phytopathologica, Botucatu, v.36, n.2, p.145-154, 2010.

10. Werber, M. Disease of Gypsophila paniculata [Polish]. Cab Abstracts, v. 39, n.12, p.6-7, 1995. 